\title{
BODY MORPHOMETRIC MEASUREMENTS IN HARMO CATTLE (RAYA-AZEBO CATLTLE) IN SOUTHERN TIGRAY OF ETHIOPIA
}

\author{
Amine MUSTEFA ${ }^{1}$, Teklewold BELAYHUN¹ ${ }^{1}$, Awoke MELAK¹, Mulata HAYELOM², Abebe HAILU1 \\ and Abraham ASSEFA ${ }^{1}$
}

1Ethiopian Biodiversity Institute, P. O. Box 30726, Addis Ababa, Ethiopia

2Mekelle Biodiversity Center, P. O. Box, 30726, Mekelle, Ethiopia

Email: aminemustefa32@gmail.com; (D) ORCiD: 0000-0003-3788-4156

supporting Information

\begin{abstract}
Twenty-four qualitative and nine quantitative variables on a total of 251 adult cattle from two purposively selected districts were recorded to characterize Harmo cattle at its natural production environment in 2019. Effect of sampled district, sex and age on the quantitative measurements and qualitative characteristics were analyzed using General linear model (GLM) procedure and non-parametric (Chi-square) test of Statistical Analysis System (SAS 9.0) respectively. The qualitative characteristics and quantitative measurements of Harmo cattle were partially affected by district, sex and age categories. Majority of Harmo cattle were horned $(100 \%)$ with lyre shaped $(83.73 \%)$ upward orientation $(92.46 \%)$ and wide horn spacing $(\geq 30$ $\mathrm{cm})(96.03 \%)$. They also possess straight edged ear (97.22\%). Harmo cattle hump was erected $(98.81 \%)$, and small (88.1\%) and found at cervical thoracic (78.57) position. The results also revealed that Harmo cattle were characterized by flat face $(99.21 \%)$, straight back profile $(88.49 \%)$, long tail $(95.24 \%)$ and large dewlap $(75 \%)$. Body color pattern of Harmo cattle was uniform $(61.11 \%)$, spotty $(26.98 \%)$ and others $(11.9 \%)$. Red and light-red were the body and head color of the majority of the studied cattle populations. Beside their large horns Harmo cows also possess medium (38.8\%) and large (42.4\%) naval flap. Similarly, the oxen also possess medium (46.4\%) and large (50\%) preputial sheath. The overall measurements of body length, Heart girth, Height at withers, Pelvic width, Muzzle circumference, Ear length, Horn length, Canon bone length, Hock circumference for Harmo oxen and cows were 127.8 $\pm 1.22,146.7 \pm 1.37,121.7 \pm 0.92,35.5 \pm 0.45,39.5 \pm 0.35,21.2 \pm 0.31$, $65.5 \pm 2.08,25.0 \pm 0.30,33.0 \pm 0.28$ and $121.3 \pm 0.43,138.9 \pm 0.48116 .5 \pm 0.32,35.0 \pm 0.16,36.9 \pm 0.12$, $21.3 \pm 0.11,61.8 \pm 0.73,24.0 \pm 0.11,31.3 \pm 0.10$, respectively. These results show Harmo cattle possess long and thin body and long ear and horn in comparison with most of the Ethiopian cattle breeds. The thin body of Harmo cattle might be due to shortage of available feed in and around the breeding tract of the breed. The long ear and horn may help them to adapt the hot bushy grazing land environment and protect themselves from the enemy existed in their natural habitat.
\end{abstract}

Keywords: Biometry, Breeding, Harmo Cattle, Morphometric characterizes, Raya-Azebo.

\section{INTRODUCTION}

Ethiopia have the largest cattle population size in Africa (60.39 million heads) without counting some zones of the highly populated Regions (Afar and Somali) (CSA, 2018). Majority of the cattle population are indigenous breeds, which are found in the rural part of the country, while some exotic and crossbreds also exist mainly in the urban and peri-urban areas (Roessler et al., 2018; Abebe et al., 2020). Beside the large population size distributed widely throughout the country, farmers and pastoralists get multiple functions from their productions and services. Cattle genetic resources serve as sources of meat, milk, hide, manure, draft power and nutrient recycling (Getachew and Gashaw, 2001).

Diversity in animal genetic resource is important for current and future research and development works. Diversity allows the indigenous genetic resources to adapt and produce in a more diversified agro ecologies. Variation with in and among breeds is also one of the key inputs in genetic improvement and conservation programs (Delgado Bermejo et al., 2019). It is more likely to bring genetic improvement in a population with high variation than low variation. This increment in production and productivity will in turn help us to answer the food security problems; market requirements and nutritional gaps. Similarly, as the variation within and among breeds increase it brings a good opportunity to find adaptable breeds to the changing agro ecology due to different factors including the climate change. Therefore, to better understand the level of diversity and potential of our indigenous animal genetic resources, proper characterization works are crucial (EBI, 2016). However, in Ethiopia there is a gap of harmonizing the characterization works, keeping proper production and reproduction records and positivity towards conservation of the indigenous animal genetic resources. 
Even if there are different sources of information like Domestic Animal Genetic Resources Information System (DAGRIS) of the International Livestock Research Institute (ILRI), based on the current available information from the country's focal institute for Animal Genetic Resources (Ethiopian Biodiversity Institute) and the website Domestic Animal Diversity Information System (DAD-IS) of the Food and Agriculture Organization of the United Nation (FAO), there are 28 recognized indigenous cattle breeds in Ethiopia (EBI, 2016). However, only a small number of recognized cattle breed types have a fair description of their physical appearance, indications of their level of production, reproduction and genetic attributes (Ayalew et al., 2004). With some general information, cattle of the present study area are generally referred as Raya-Azebo (Raya) cattle in the existing literature. Raya-Azebo cattle also locally known as 'Harmo' cattle breed found in Southern Tigray which is one of the cattle breeds classified under the Sanga breed group. Harmo cattle is known for its long horns and adaptation to hot environment (Zerabruk et al. 2007).

Most of the Ethiopian indigenous animal genetic resources are facing more threats including the indiscriminate crossbreeding with exotic breeds for the sake of genetic improvement for production traits (EBI, 2016). Harmo cattle is one of the breeds which is under risk due to indiscriminate crossbreeding with Holstein Frisian and interbreeding with the highland zebus. For the purpose of designing conservation and sustainable utilization program to the breed, updated information on phenotypic characterization (quantitative, qualitative and performance records) is required. Unfortunately, the information we have currently on the breed is the studies of Zerabruk et al. (2007) on few morphometric traits which is done twelve years ago. Therefore, it is important to update the results through routine characterization and inventories due to the dynamism of genetic resources (Hoffmann, 2010; Lozano-Jaramillo et al., 2019). Thus, the current study is planned to characterize the morphology and qualitative characteristics of Harmo cattle under the farmers' condition and to relate it with different production and adaptation traits.

\section{MATERIALS AND METHODS}

\section{Description of the study areas}

This study was conducted in Raya Azebo and Alamata districts of Southern Tigray Zone in Northern Ethiopia in 2019 (Figure 1). Raya Azebo is situated in latitude of $12^{\circ} 39^{\prime} 59.99^{\prime \prime} \mathrm{N}$ and longitude of $39^{\circ} 44^{\prime} 59.99 " \mathrm{E}$, similarly, Alamata is also situated in latitude of $12^{\circ} 19^{\prime} 60.00^{\prime \prime} \mathrm{N}$ and longitude of $39^{\circ} 29^{\prime} 59.99^{\prime \prime} \mathrm{E}$. The selected study sites (three sites "Kebeles" within each district) are categorized as lowland (500 - 1500 m.a.s.I) with $20-30{ }^{\circ} \mathrm{C}$ and dry with mean annual rainfall 633 - $770 \mathrm{ml}$. Mixed crop-livestock production system is the main farming practices with crops being more dominant (Taddese et al., 2013; Bewket et al., 2015). 


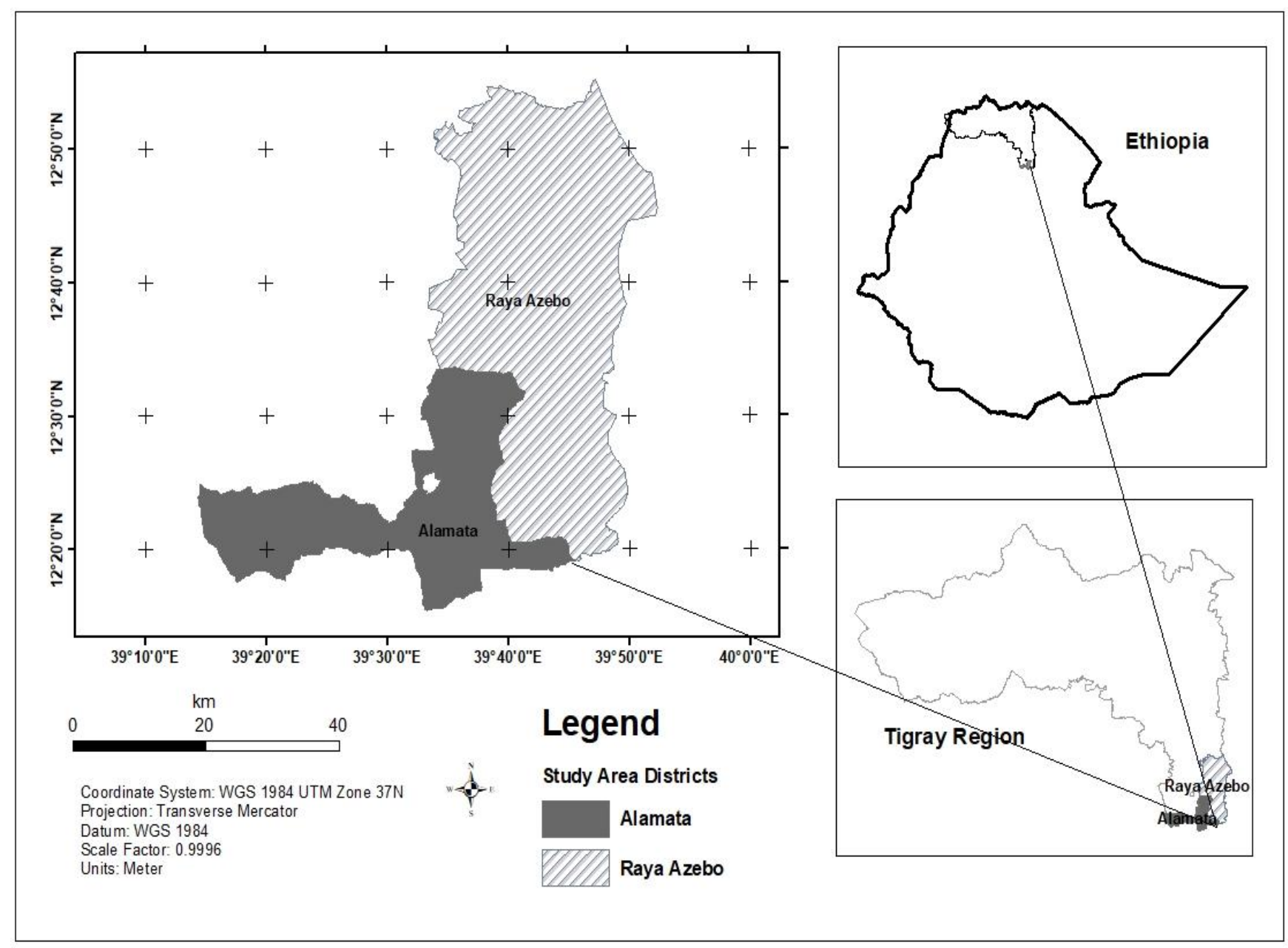

\section{Figure 1- Map of the study areas}

\section{Site selection and sampling method}

In defining sampling frame, available background information on the existence Raya cattle in the study area was captured through short pilot survey and focus group discussions done by a team of Ethiopian Biodiversity Institute researchers and livestock experts from Southern Tigray zone, Raya Azebo and Alamata districts. Additionally, the information (origin of Harmo cattle, its unique features and densely populated areas) of the earlier study done by Zerabruk et al. (2007) was also taken as an input to select study areas. For the purpose of selecting pure Harmo cattle, the cattle populations from the high and mid altitude areas within the districts were not considered, as they did not show distinct features due to the interbreeding with the highland cattle populations. Therefore, samples were not taken from high and mid-altitude areas. Six study kebeles were selected purposively taking into account the cattle population size, dominant agro-ecology, and indigenous knowledge on cattle population types. Male to female ratio (28 oxen and 223 cows) of the sampled animals were adapted from FAO guideline for Animal Genetic Resource Characterization (FAO, 2012). Animals were randomly selected from herds of representative households.

\section{Table 1 - Sampled number of animals by district and by age and their proportion.}

\begin{tabular}{|c|c|c|c|c|c|}
\hline \multirow{2}{*}{ District / Location } & \multicolumn{3}{|c|}{ Age } & \multirow{2}{*}{ Total } & \multirow{2}{*}{ Proportion } \\
\hline & $3-5$ years & $6-7$ years & $\geq 8$ years & & \\
\hline Raya Azebo & 44 & 50 & 32 & 126 & 0.50 \\
\hline Raya Alamata & 35 & 50 & 40 & 125 & 0.50 \\
\hline Total & 79 & 100 & 72 & 251 & 1.00 \\
\hline Proportion & 0.31 & 0.40 & 0.29 & 1.00 & - \\
\hline
\end{tabular}

\section{Data collection}

Twenty-four qualitative traits (horn presence, horn spacing, horn shape, horn orientation, body color pattern, body color, head color, muzzle pigment, eyelid pigment, hoof pigment, ear shape, hump shape, hump size, hump position, udder size, teat size, face profile, back profile, rump profile, testes size, tail length, naval flap width, preputial sheath and dewlap width), and nine quantitative measurements (body length, heart girth, height at wither, pelvic width, muzzle circumference, ear length, horn length, canon bone length and hock circumference) were recorded from 251 mature 
animals under the effect of district, sex and age of each sampled animal. For the purpose of analysis age groups were categorized in to three; group one 3 - 5 years, group two $6-7$ years and group three 8 years and above as per the grouping of Tatum (2011). For the body measurements, animals were carefully handled by trained laborers and stand properly on flat grounds with parallel legs. Animals which were aggressive and did not stand properly were not measured. The measurements were carried out by two researchers: one measuring while the other recording data. On the same time, two other researchers handle the qualitative data recording. To minimize the subjective error, all the measurements were taken by the same researcher throughout the study. Quantitative measurements were taken using textile tape measurement in centimeter unit, and early in the morning before the animals were fed and watered.

\section{Data management and analysis}

Data were entered and managed using Microsoft Excel( ) worksheet. Outliers were corrected after running normality test procedure of Statistical Analysis Software 9.0 (SAS, 2002). Analysis of data on quantitative measurements was carried out using the General Linear Model procedure of SAS 9.0 software. Means were separated using the adjusted Tukey-Kramer test (SAS, 2002). Similarly, analysis of qualitative data was carried out using the frequency procedure (chisquare test) of SAS 9.0 software. The model used for the analysis was: Yijk $=\mu+A i+B j+C k+e i j k$, Where Yijk is an observation, $\mu$ is the overall mean, $\mathrm{Ai}$ is the fixed effect of district, $\mathrm{Bj}$ is the fixed effect of the sex, Ck is the fixed effect of age group and eijk is the random error attributed to the nth observation. Due to the non-significant effects of the interactions among the above factors, it was removed from the analysis and results. Traits like udder size, teat size and naval flap width were analyzed for females only by eliminating the males and fitting district and age as fixed factors while traits like testes size and preputial sheath were analyzed for males only by eliminating the females from the analysis fitting district and age as fixed factors.

\section{RESULTS}

\section{Quantitative measurements}

The overall mean, standard error (SE), standard deviation (SD), minimum, maximum and coefficients of variation (CV) of the measured quantitative traits are presented in Table 2. For all morphometric traits measured the coefficient of variation was within the range of 4.26 and 7.80 . Relatively higher coefficient of variation (18.87\%) was calculated for horn length implying higher variation in terms of horn length. The difference between the minimum and maximum value is sizeable in most cases. A range of $54 \mathrm{~cm}$ for heart girth, $37 \mathrm{~cm}$ for body length, $28 \mathrm{~cm}$ for height at withers, and a range of about $62 \mathrm{~cm}$ for horn length were observed. The results show there were high variations among Harmo cattle over the measured quantitative traits which is a better ground for genetic improvement due to selection.

Least square means, standard error (SE), and pairwise comparison of the measured quantitative traits under the effects of district, sex and age are presented in Table 3 and 4. Sampled district had a significant $(p<0.01)$ effect on five of the total nine measured traits and it is indicated that four of the body measurements were higher for the cattle population of Alamata. Based on this, cattle population of Alamata district had larger muzzle and hock, and longer ear and horn than the cattle populations of Raya Azebo. However, the canon of the cattle from Raya Azebo was longer than those of Alamata. Similarly, sex of the cattle populations affected six out of the nine measured traits indicating oxen had longer body, height at wither, canon and heart girth measurements than the cows. Significant differences were not recorded between the two sexes in pelvic width, ear length and horn length.

The results also revealed that four out of the nine measurements were affected by age of the cattle population. Based on this, slight increment in pelvic width, muzzle circumference, ear and horn length was observed as the age of the cattle population increases.

\section{Table 2 - Overall mean (cm), SE, SD, CV, Minimum and Maximum body measurements of Harmo cattle breed.}

\begin{tabular}{lccccc} 
Variables & Overall mean \pm SE & SD & Minimum & Maximum & CV \\
\hline Body length & $122.0 \pm 0.42$ & 6.65 & 106 & 143 & 5.45 \\
Heart girth & $139.8 \pm 0.46$ & 7.45 & 114 & 168 & 5.33 \\
Height at withers & $117.1 \pm 0.31$ & 4.98 & 102 & 130 & 4.26 \\
Pelvic width & $35.0 \pm 0.15$ & 2.42 & 28 & 42 & 6.90 \\
Muzzle circumference & $37.2 \pm 0.13$ & 2.01 & 31 & 44 & 5.41 \\
Ear length & $21.3 \pm 0.11$ & 1.66 & 16 & 25 & 7.80 \\
Horn length & $62.1 \pm 0.74$ & 11.72 & 30 & 92 & 18.87 \\
Canon bone length & $24.1 \pm 0.11$ & 1.66 & 19 & 29 & 6.90 \\
Hock circumference & $31.5 \pm 0.10$ & 1.55 & 28 & 35 & 4.91 \\
SE = Standard Error, SD = Standard Deviation, CV = Coefficient of variation & & & & &
\end{tabular}


Table 3 - Least square means (cm) with standard error and pairwise comparison of body measurements in each district and sex category

\begin{tabular}{|c|c|c|c|c|c|c|}
\hline \multirow{2}{*}{ Variables } & \multicolumn{3}{|c|}{ District } & \multicolumn{3}{|c|}{ Sex } \\
\hline & Raya Azebo & Alamata & $p$ - value & Male & Female & $p$-value \\
\hline $\mathbf{N}$ & 126 & 125 & & 28 & 223 & \\
\hline BL & $124.2 \pm 0.72$ & $125.1 \pm 0.81$ & 0.3086 & $127.8 \pm 1.22$ & $121.3 \pm 0.43$ & $<0.0001$ \\
\hline$H G$ & $142.4 \pm 0.80$ & $143.3 \pm 0.91$ & 0.3049 & $146.7 \pm 1.37$ & $138.9 \pm 0.48$ & $<0.0001$ \\
\hline HW & $119.0 \pm 0.54$ & $119.1 \pm 0.61$ & 0.8021 & $121.7 \pm 0.92$ & $116.5 \pm 0.32$ & $<0.0001$ \\
\hline PW & $35.39 \pm 0.27$ & $35.0 \pm 0.30$ & 0.2376 & $35.5 \pm 0.45$ & $35.0 \pm 0.16$ & 0.2652 \\
\hline MC & $37.91 \pm 0.21$ & $38.9 \pm 0.23$ & 0.0150 & $39.5 \pm 0.35$ & $36.9 \pm 0.12$ & $<0.0001$ \\
\hline EL & $21.00 \pm 0.18$ & $21.5 \pm 0.21$ & 0.0226 & $21.2 \pm 0.31$ & $21.3 \pm 0.11$ & 0.6493 \\
\hline HL & $61.53 \pm 1.22$ & $65.8 \pm 1.37$ & 0.0024 & $65.5 \pm 2.08$ & $61.8 \pm 0.73$ & 0.0889 \\
\hline CBL & $24.91 \pm 0.18$ & $24.1 \pm 0.20$ & $<0.0001$ & $25.0 \pm 0.30$ & $24.0 \pm 0.11$ & 0.0024 \\
\hline $\mathrm{HC}$ & $31.85 \pm 0.16$ & $32.4 \pm 0.18$ & 0.0016 & $33.0 \pm 0.28$ & $31.3 \pm 0.10$ & $<0.0001$ \\
\hline
\end{tabular}

Table 4 - Least square means (cm) and pairwise comparison of body measurements with standard error in each age category

\begin{tabular}{|c|c|c|c|c|}
\hline \multirow{2}{*}{ Variables } & \multicolumn{3}{|c|}{ Age } & \multirow{2}{*}{$p$ - value } \\
\hline & $3-5$ years & 6 - 7 years & $\geq 8$ years & \\
\hline $\mathbf{N}$ & 79 & 100 & 72 & \\
\hline Body length & $123.5 \pm 0.83$ & $124.5 \pm 0.83$ & $126.0 \pm 0.93$ & 0.0548 \\
\hline Heart girth & $142.1 \pm 0.93$ & $143.0 \pm 0.93$ & $143.3 \pm 1.04$ & 0.5625 \\
\hline Height at withers & $118.6 \pm 0.62$ & $119.4 \pm 0.62$ & $119.2 \pm 0.70$ & 0.4873 \\
\hline Pelvic width & $34.3 \pm 0.31^{b}$ & $35.6 \pm 0.31^{a}$ & $35.8 \pm 0.34^{a}$ & 0.0001 \\
\hline Muzzle circumference & $37.6 \pm 0.24^{b}$ & $38.2 \pm 0.24^{b}$ & $38.8 \pm 0.27^{a}$ & 0.0003 \\
\hline Ear length & $20.9 \pm 0.21^{b}$ & $21.5 \pm 0.21^{a}$ & $21.3 \pm 0.23^{a b}$ & 0.0246 \\
\hline Horn length & $57.8 \pm 1.41^{c}$ & $64.6 \pm 1.41^{b}$ & $68.6 \pm 1.58^{a}$ & $<0.0001$ \\
\hline Canon bone length & $24.5 \pm 0.21$ & $24.4 \pm 0.21$ & $24.6 \pm 0.23$ & 0.7706 \\
\hline Hock circumference & $31.9 \pm 0.19$ & $32.1 \pm 0.19$ & $32.4 \pm 0.21$ & 0.1530 \\
\hline
\end{tabular}

\section{Qualitative characteristics}

The overall Harmo cattle qualitative characteristics by district, sex and age are presented under Tables 5 - 7. Majority of the cattle population were horned (100\%) with lyre shaped (83.73\%) upward orientation (92.46) and wide horn spacing $(\geq 30 \mathrm{~cm})(96.03 \%)$. They also possess straight edged ear $(97.22 \%)$. Harmo cattle hump was erected (98.81\%), and small (88.1\%), and found at cervical thoracic (78.57) position. The results also revealed that Harmo cattle population had flat face $(99.21 \%)$ and straight back profile $(88.49 \%)$, long tail $(95.24 \%)$ and large dewlap (75\%). Body color pattern of Harmo cattle population was uniform (61.11\%), spotty (26.98\%) and others (11.9\%). Red and light-red body and head color was observed on majority of the cattle. Beside their large horns Harmo cows also possess medium (38.8\%) and large (42.4\%) naval flap. Similarly, the oxen also possess medium $(46.4 \%)$ and large (50\%) preputial sheath. The qualitative characteristics of Harmo cattle were partially affected by district, sex and age categories.

Table 5 - Qualitative characteristics of Harmo cattle under district and sex effect

\begin{tabular}{|c|c|c|c|c|c|c|}
\hline \multirow{2}{*}{ Variables } & \multicolumn{3}{|c|}{ District } & \multicolumn{3}{|c|}{ Sex } \\
\hline & Raya Azebo & Alamata & $P$-value & Male & Female & $P$-value \\
\hline Horn spacing & & & 1.00 & & & 0.9092 \\
\hline Narrow & 4.0 & 4.0 & & 3.6 & 4.0 & \\
\hline Wide & 96.0 & 96.0 & & 96.4 & 96.0 & \\
\hline Horn shape & & & 0.8645 & & & 0.7629 \\
\hline Curvy & 15.9 & 16.7 & & 14.3 & 16.5 & \\
\hline Lyre & 84.1 & 83.3 & & 85.7 & 83.5 & \\
\hline Horn orientation & & & 0.2329 & & & 0.3989 \\
\hline Forward & 5.6 & 9.5 & & 3.6 & 8.0 & \\
\hline Upward & 94.4 & 90.5 & & 96.4 & 92.0 & \\
\hline Ear shape & & & 0.0073 & & & 0.0067 \\
\hline Round edged & 5.6 & 0.0 & & 10.7 & 1.8 & \\
\hline
\end{tabular}




\begin{tabular}{|c|c|c|c|c|c|c|}
\hline Straight edged & 94.4 & 100 & & 89.3 & 98.2 & \\
\hline Hump shape & & & 0.2227 & & & 0.0003 \\
\hline No Hump & 0.8 & 0 & & 0 & 0.5 & \\
\hline Erect & 99.2 & 98.4 & & 92.9 & 99.5 & \\
\hline Dropping & 0 & 1.6 & & 7.1 & 0 & \\
\hline Hump size & & & 0.0368 & & & $<0.0001$ \\
\hline No Hump & 0.8 & 0 & & 0 & 0.5 & \\
\hline Small & 92.8 & 83.3 & & 71.4 & 90.1 & \\
\hline Medium & 6.4 & 14.3 & & 17.9 & 9.4 & \\
\hline Large & 0 & 2.4 & & 10.7 & 0 & \\
\hline Hump position & & & $<0.0001$ & & & $<0.0001$ \\
\hline No Hump & 0.8 & 0 & & 0 & 0.5 & \\
\hline Thoracic & 33.3 & 8.7 & & 78.6 & 13.8 & \\
\hline Cervical thoracic & 65.9 & 91.3 & & 21.4 & 85.7 & \\
\hline Face profile & & & 0.3649 & & & 0.0170 \\
\hline Flat & 98.4 & 100 & & 96.4 & 99.5 & \\
\hline Concave & 0.8 & 0 & & 0 & 0.5 & \\
\hline Convex & 0.8 & 0 & & 3.6 & 0 & \\
\hline Back profile & & & $<0.0001$ & & & 0.0176 \\
\hline Curved & 19.8 & 3.2 & & 25.0 & 9.8 & \\
\hline Straight & 80.2 & 96.9 & & 75.0 & 90.2 & \\
\hline Tail length & & & 0.3995 & & & 0.2069 \\
\hline Short & 0.8 & 0.00 & & 0.00 & 0.45 & \\
\hline Medium & 3.2 & 5.56 & & 10.71 & 3.57 & \\
\hline Long & 96.0 & 94.44 & & 89.29 & 95.98 & \\
\hline Dewlap width & & & 0.6625 & & & 0.6434 \\
\hline Small & 0 & 0 & & 0 & 0 & \\
\hline Medium & 23.8 & 26.2 & & 21.4 & 25.5 & \\
\hline Large & 76.2 & 73.8 & & 78.6 & 74.5 & \\
\hline
\end{tabular}

\section{District effect}

The study shows effect of district on four out of the twenty-four qualitative traits recorded. Based on this, some round edged ear shape was found in Raya Azebo while all the cattle populations from Alamata had straight edged ear. One third of the cattle populations from Raya Azebo possess thoracic hump position while almost all the cattle from Alamata had cervical thoracic hump position. One fifth of the Raya Azebo cattle's back profile was curved while straight back profile was observed on almost all Alamata cattle populations.

\section{Table 6 - Qualitative characteristics of Harmo cattle under age effect}

\begin{tabular}{|c|c|c|c|c|c|}
\hline \multirow{2}{*}{ Variables } & \multirow[b]{2}{*}{ Overall \% (N) } & \multicolumn{4}{|c|}{ Age } \\
\hline & & $3-5$ & $6-7$ & $\geq 8$ & $P$-value \\
\hline Horn spacing & & & & & 0.0721 \\
\hline Narrow & $4.0(10)$ & 0.0 & 5.0 & 6.9 & \\
\hline Wide & $96.0(242)$ & 100 & 95 & 93.1 & \\
\hline Horn shape & & & & & 0.0284 \\
\hline Curvy & $16.3(41)$ & 25.0 & 14.0 & 9.7 & \\
\hline Lyre & $83.7(211)$ & 75.0 & 86.0 & 90.3 & \\
\hline Horn orientation & & & & & 0.0286 \\
\hline Forward & 7.5(19) & 13.7 & 6.0 & 2.8 & \\
\hline Upward & 92.5(233) & 86.3 & 94.0 & 97.2 & \\
\hline Ear shape & & & & & 0.9796 \\
\hline Round edged & $2.8(7)$ & 2.50 & 3.0 & 2.8 & \\
\hline Straight edged & $97.2(245)$ & 97.50 & 97.0 & 97.2 & \\
\hline Hump shape & & & & & 0.2111 \\
\hline No Hump & $0.4(1)$ & 0 & 1.0 & 0 & \\
\hline Erect & $98.8(249)$ & 97.5 & 99.0 & 100 & \\
\hline Dropping & $0.8(2)$ & 2.5 & 0 & 0 & \\
\hline Hump size & & & & & 0.1849 \\
\hline No Hump & $0.4(1)$ & 0 & 1.0 & 0 & \\
\hline
\end{tabular}




\begin{tabular}{|c|c|c|c|c|c|}
\hline Small & $88(222)$ & 81.2 & 89.0 & 94.4 & \\
\hline Medium & $10.3(26)$ & 16.3 & 9.0 & 5.6 & \\
\hline Large & $1.3(3)$ & 2.5 & 1.0 & 0 & \\
\hline Hump position & & & & & 0.2224 \\
\hline No Hump & $0.4(1)$ & 0 & 1.0 & 0 & \\
\hline Thoracic & 21(53) & 28.8 & 18.0 & 16.7 & \\
\hline Cervical thoracic & $78.6(198)$ & 71.2 & 81.0 & 83.3 & \\
\hline Face profile & & & & & 0.3626 \\
\hline Flat & $99.2(250)$ & 97.5 & 100 & 100 & \\
\hline Concave & $0.4(1)$ & 1.3 & 0 & 0 & \\
\hline Convex & $0.4(1)$ & 1.2 & 0 & 0 & \\
\hline Back profile & & & & & 0.7988 \\
\hline Curved & $11.5(29)$ & 11.3 & 13.0 & 9.7 & \\
\hline Straight & $88.5(223)$ & 88.7 & 87.0 & 90.3 & \\
\hline Tail length & & & & & 0.4592 \\
\hline Short & $0.4(1)$ & 0.00 & 0.00 & 1.39 & \\
\hline Medium & $4.4(11)$ & 3.75 & 6.00 & 2.78 & \\
\hline Long & $95.2(240)$ & 96.25 & 94.00 & 95.83 & \\
\hline Dewlap width & & & & & 0.9383 \\
\hline Small & $0(0)$ & 0 & 0 & 0 & \\
\hline Medium & $25.0(63)$ & 25.0 & 24.0 & 26.4 & \\
\hline Large & $75.0(189)$ & 75.0 & 76.0 & 73.6 & \\
\hline
\end{tabular}

\section{Sex and age effect}

The study also revealed that cattle sex affects six out of the twenty-four qualitative traits recorded. Based on this, some of the Harmo oxen had round edged ear and dropping hump shape while almost all cows had straight edged ear and erect hump shape. About one third of the oxen had medium to large hump while almost all cows possess small hump. Most oxen possess hump at the thoracic position while most cows had cervical thoracic hump position. Curved back profile was observed on one fourth of the oxen while most of the cows possess straight back profile. The results also show effect of age categories (five out of twenty-four) on the recorded qualitative traits. Based on this, horn of the cattle populations tends to be upward lyre shape as they get aged. Similarly, naval flap width, udder and teat size of the cows becomes large and long as their age progress. Harmo oxen possess small testes and medium to long preputial sheath, while, the cows had medium udder and teat size and medium to large naval flap width.

Table 7 - Body color and sex-limited characteristics of Harmo cattle under the effect of district, age and sex.

\begin{tabular}{|c|c|c|c|c|c|c|c|c|}
\hline \multirow{2}{*}{ Variables } & \multirow{2}{*}{$\begin{array}{l}\text { Overall \% } \\
\text { (N) }\end{array}$} & \multicolumn{2}{|c|}{ District } & \multicolumn{3}{|c|}{ Age } & \multicolumn{2}{|c|}{ Sex } \\
\hline & & Raya Azebo & Alamata & $3-5$ & $6-7$ & $\geq 8$ & Male & Female \\
\hline Body color pattern & & \multicolumn{2}{|c|}{$P=0.7515$} & \multicolumn{3}{|c|}{$P=0.1069$} & \multicolumn{2}{|c|}{$P=0.1253$} \\
\hline Uniform & 61.1(154) & 57.9 & 64.3 & 57.5 & 67.0 & 56.9 & 46.4 & 63.0 \\
\hline Spotty & $27.0(68)$ & 28.6 & 25.3 & 31.2 & 17.0 & 36.1 & 28.6 & 26.7 \\
\hline Pied & $7.1(18)$ & 7.9 & 6.4 & 6.3 & 10.0 & 4.2 & 14.3 & 6.3 \\
\hline Shaded & $4.8(12)$ & 5.6 & 4.0 & 5.0 & 6.0 & 2.8 & 10.7 & 4.0 \\
\hline Body color & & \multicolumn{2}{|c|}{$P=0.9460$} & \multicolumn{3}{|c|}{$P=0.6168$} & \multicolumn{2}{|c|}{$P=0.4588$} \\
\hline Red & $38.9(98)$ & 39.7 & 38.1 & 37.50 & 42.0 & 36.1 & 42.8 & 38.4 \\
\hline Light red & $14.3(36)$ & 12.7 & 15.9 & 11.25 & 17.0 & 13.9 & 3.6 & 15.6 \\
\hline Black & $8.7(22)$ & 7.1 & 10.3 & 7.50 & 7.0 & 12.5 & 3.6 & 9.4 \\
\hline Black + White & $16.3(41)$ & 17.5 & 15.1 & 20.00 & 12.0 & 18.1 & 25.0 & 15.2 \\
\hline Black + Red & 7.1(18) & 7.9 & 6.4 & 6.25 & 10.0 & 4.2 & 10.7 & 6.7 \\
\hline Red + White & $11.5(29)$ & 11.9 & 11.1 & 13.75 & 8.0 & 13.9 & 10.7 & 11.6 \\
\hline White & $3.2(8)$ & 3.2 & 3.2 & 3.75 & 4.0 & 1.4 & 3.6 & 3.1 \\
\hline Testes size & & \multicolumn{2}{|c|}{$P=0.2062$} & \multicolumn{3}{|c|}{$P=0.2734$} & & \\
\hline Small & $67.9(19)$ & 71.4 & 57.1 & 50.0 & 88.9 & 80.0 & & \\
\hline Medium & $21.4(6)$ & 23.8 & 14.3 & 28.6 & 11.1 & 20.0 & & \\
\hline Large & $10.7(3)$ & 4.8 & 28.6 & 21.4 & 0 & 0 & & \\
\hline Preputial sheath & & \multicolumn{2}{|c|}{$P=0.4002$} & \multicolumn{3}{|c|}{$P=0.5359$} & & \\
\hline
\end{tabular}




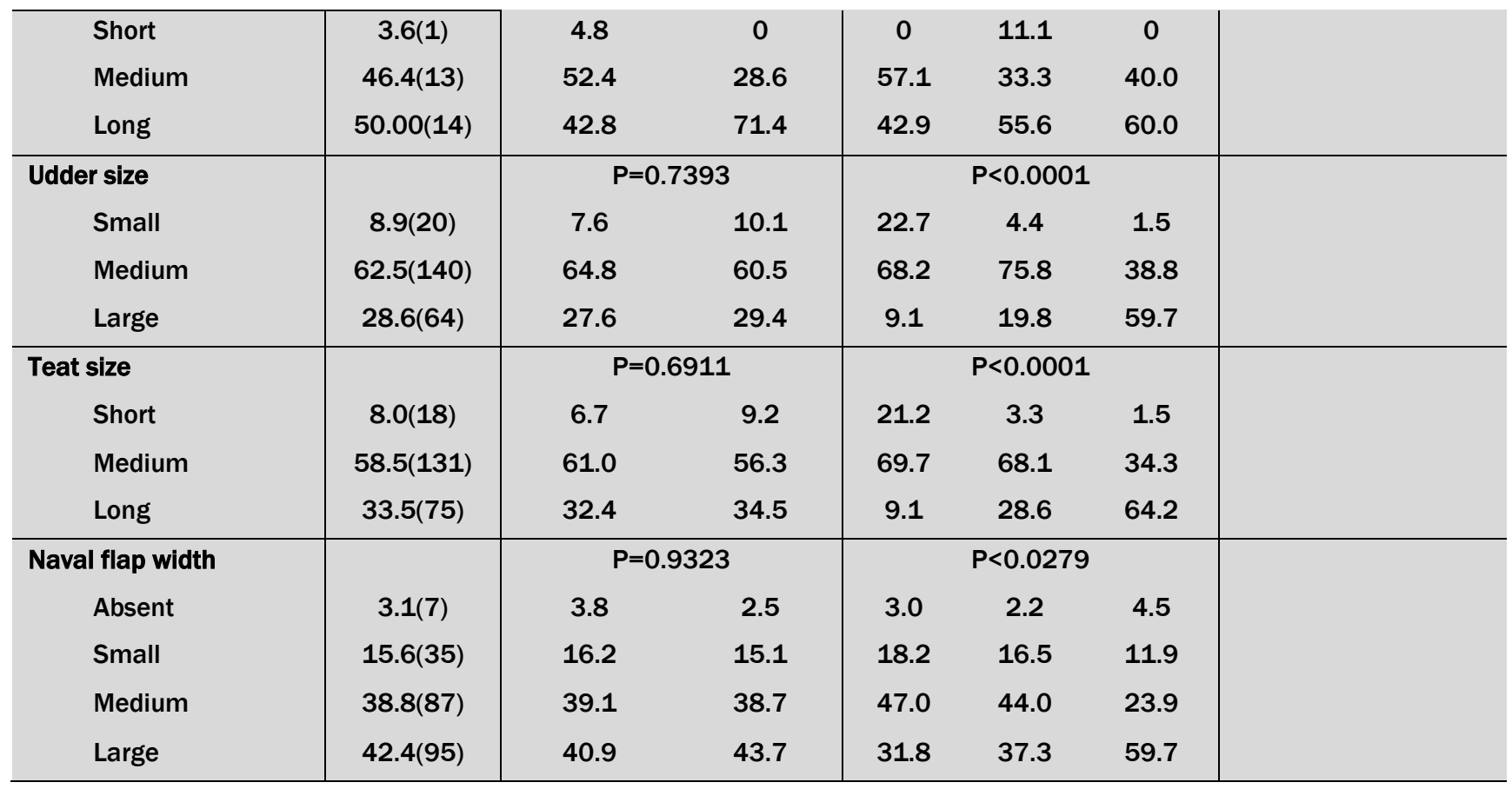

\section{DISCUSSION}

\section{Quantitative measurements}

Oxen were dominant over cows on most of the measurements, which follow the Rensch's rule (Rensch, 1950) where the males of a particular species are usually larger than the females. The differences between the oxen and cows may be further ascribed to the testosterone hormones secreted within the oxen which leads to enhancement of muscle mass and skeletal development (Baneh and Hafezian, 2009). The sexual dimorphism of the animals may be ascribed to the differences in the endocrine system of the two sexes; estrogen hormone has a limited effect for growth in females (Chriha \& Ghadri, 2001; Baneh and Hafezian, 2009). The results were in line with the results of Genzebu et al. (2012) on Arado cattle and Endashaw et al. (2015) on Mursi cattle who reported that oxen were larger than cows. Similarly, dominance of bucks over does were reported in Ethiopia (Mustefa et al., 2019).
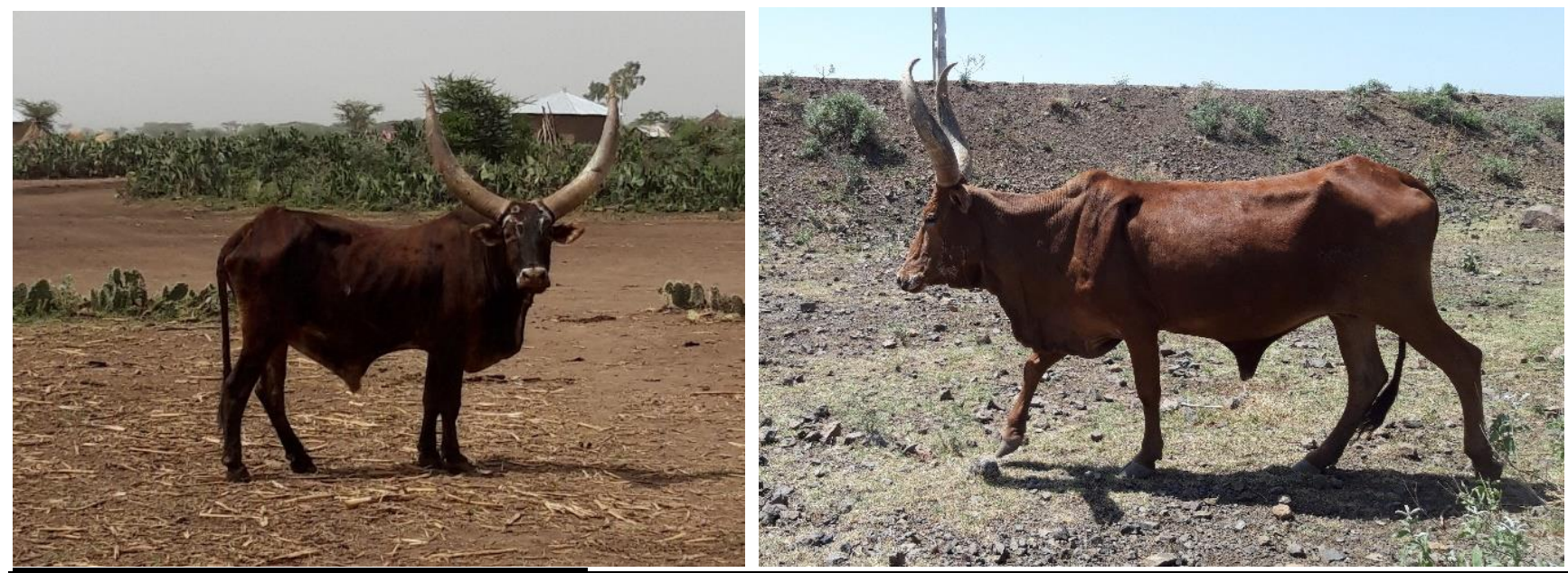

Even if, Raya Azebo (Figure 2) was the reported origin of Harmo cattle populations, most of the quantitative measurement results show cattle populations from Alamata district were larger than those of Raya Azebo. This might be due to the long term interbreeding with the Ethiopian highland breeds. These results were also in line with the results of Endashaw et al. (2015) on Mursi cattle who reported differences within the same cattle breed among different districts. Age differences count a little on the observed differences in quantitative measurements which might be due to the nature of the sampling (selecting adult animals only), however, increment in horn length was observed as the animals get aged.

Harmo cattle breed had longer and tall body than Horro, Sheko, Arado and Ogaden cattle breeds however some other cattle breed like Begait possess longer and taller body than Harmo cattle (Takele et al., 2007; Dessalegn et al., 2012; Fasil et al., 2014 and Mulugeta, 2015). Hearth girth measurements of Harmo breed was lower than Ogaden, Arsi and Begait cattle breeds. However, Harmo cattle were one of the Ethiopian indigenous cattle genetic resources which 
possess large horns and ears. These results also show Harmo cattle breed possess long and thin body, and long ear and horn in comparison to most of the Ethiopian cattle breeds. The thin body of Harmo cattle might be due to shortage of available feed in and around the breeding tract of the breed. The long ear and horn may help them to adapt the hot bushy grazing land environment and protect themselves from the enemy existed in their natural habitat.

\section{Qualitative characteristics}

Too much significant differences in qualitative characteristics was not observed among the two sampling districts and the three age categories, which shows how unique characteristics the cattle populations from the different district and age categories share. These results are in line with the results of Endashaw et al. (2015) who observed similar qualitative characteristics among the different sampling location within the Mursi cattle breed. On the other hand, some effects of sex on the qualitative characteristics was observed which might be due to the sexual dimorphism which follow the Rensch's rule (Rensch, 1950).

\section{Conclusion}

Harmo (Raya-Azebo) cattle populations were characterized in 2019 based on FAO guidelines to update the available information for in-situ conservation purpose. Accordingly, two districts were covered; Raya Azebo and Alamata. Sizable variations were recorded among the sampled animals, which may help the further in-situ conservation and genetic improvement program. Partial effects of district, sex and age were observed. Based on these results, the cattle population from Alamata district were partially dominant over their Raya Azebo counterparts in some quantitative variables. Similarly, males were dominant over females in most of the studied variables. On the other hand, slight increment in the quantitative variables were recorded as the age of the cattle increases. The overall results show Harmo cattle possess long and thin body, and long ear and horn in comparison with most of the Ethiopian cattle breeds. The thin body of Harmo cattle might be due to shortage of available feed in and around the breeding tract of the breed. The long ear and horn may help them to adapt the hot bushy grazing land environment and protect themselves from the enemy existed in their natural habitat.

\section{DECLARATIONS}

\section{Corresponding Author}

E-mail: aminemustefa32@gmail.com

\section{Authors' Contribution}

All authors contributed to the study conception and design. AM, TB, AM, and MH collect data. Amine Mustefa contribute on data analysis and the write up of the manuscript. AH and AA review the manuscript. All authors read and approved the final manuscript.

\section{Conflict of interests}

The authors have not declared any conflict of interests.

\section{Acknowledgements}

The authors are highly indebted to the Ethiopian Biodiversity Institute (EBI) for covering all the budget needs of the work. Our special appreciation also goes to the smallholder farmers /breeders for providing their animal to this work for free. We also take this opportunity to thank the animal science experts and development agents in the district for their endless help during the data collection. A special word also goes to our friend and work partner Mr. Tadesse Hunduma for mapping the study area.

\section{REFERENCES}

Abebe AS, Alemayehu K, Johansson AM, Gizaw S (2020). Breeding practices and trait preferences of smallholder farmers for indigenous sheep in the northwest highlands of Ethiopia: Inputs to design a breeding program. PLOS One, 15(5): e0233040. https://doi.org/10.1371/journal.pone.0233040

Baneh H and Hafezian S H (2009) Effect of environmental factor on growth traits in Ghezel sheep. African Journal of Bio-technology, 8: 2903-2907. https://doi.org/10.5897/AJB09.284

Bewket W, Radeny M, and Mungai C (2015) Agricultural Adaptation and Institutional Responses to Climate Change Vulnerability in Ethiopia. CCAFS Working Paper no. 106. CGIAR Research Program on Climate Change, Agriculture and Food Security (CCAFS). Copenhagen, Denmark. Available online at: www.ccafs.cgiar.org

Chriha A and Ghadri G (2001). Caprine in the Arab world. 2. ed. Department of Livestock Production. Fateh University: Libby Conservation of Biodiversity and Environments in the Arab Countries. 478p. Google Scholar

CSA (Central Statistical Agency) (2018). Federal Democratic Republic of Ethiopia Agricultural Sample Survey Volume II Report on Livestock and Livestock Characteristics. https://www.worldcat.org/title/agricultural-sample-survey-volume-ii-report-on-livestockand-livestock-characteristics-private-peasant-holdings/oclc/58954342

Dejenie T. Legese K, Tomas Z and Kiros S (2013). Index of Potential Contamination for Intestinal Schistosomiasis among School Children of Raya Alamata District, Northern Ethiopia. Momona Ethiopian Journal of Science (MEJS), 5(2):32-48. https://doi.org/10.4314/mejs.v5i2.91489

Delgado Bermejo JV, Martínez Martínez MA, Rodríguez Galván G, Stemmer A, Navas González FJ, and Camacho Vallejo ME. (2019) Organization and management of conservation programs and research in domestic animal genetic resources. Diversity, 11 : 235. https://doi.org/10.3390/d11120235 
EBI (Ethiopian Biodiversity Institute) (2016). Ethiopian National Strategy and Plan of Action for conservation and utilization of Animal Genetic Resources. Addis Ababa, Ethiopia. Link

Endashaw T, Tadelle D, Aynalem H, Wudyalew M and Okeyo M (2015). On-farm phenotypic characterization of Mursi cattle in its production environment in South Omo Zone, Southwest Ethiopia. Animal Genetic Resources, Food and Agriculture Organization of the United Nations. 10p. http://www.fao.org/3/a-i5198t.pdf

FAO (Food and Agricultural Organization of the United Nations) (2012). Phenotypic characterization of animal genetic resources. Food and Agriculture Organization of United Nations. Rome, Italia. http://www.fao.org/3/a-i4787e.pdf

Fasil G, Solomon A, Manaye M and Tesfu F T (2014). On-farm phenotypic characterization of Ogaden cattle populations of Jigjiga zone, southeastern Ethiopia. Ethiopian Journal of Animal Production, 14:66 - 83. Link I Google Scholar

Genzebu D, Hailemariam M and Belihu K (2012) Morphometric characteristics and livestock keeper perceptions of "Arado" cattle breed in Northern Tigray, Ethiopia. Livestock Research for Rural Development, 24: Article \#6. http://www.Irrd.org//rrd24/1/hail24006.htm

Hoffmann I (2010). Climate change and the characterization, breeding and conservation of animal genetic resources. Animal Genetics, 41: 32-46. https://doi.org/10.1111/j.1365-2052.2010.02043.x

Lozano-Jaramillo M, Bastiaansen J, Dessie,T, and Komen H (2019). Use of geographic information system tools to predict animal breed suitability for different agro-ecological zones. Animal, 13(7): 1536-1543. https://doi.org/10.1017/S1751731118003002

Mulugeta FG (2015). Production system and phenotypic characterization of Begait cattle, and effects of supplementation with concentrate feeds on milk yield and composition of Begait cows in Humera ranch, Western Tigray, Ethiopia. PhD Dissertation Addis Ababa University, Debre Zeit, Ethiopia. 114p. Google Scholar

Mustefa A, Gizaw S, Banerjee S, Abebe A, Taye M, Areaya A and Besufekad S (2019) Growth performance of Boer goats and their F1 and F2 crosses and backcrosses with Central Highland goats in Ethiopia. Livestock Research for Rural Development, 31: Article \#89. http://www.Irrd.org/Irrd31/6/amine31089.html

Rensch B (1950). Die Abhangigkeit der relative sexual differenz von der korpergrosse. Bonner Zoologische Beitrage, 1: 58 - 69.

Roessler R, Mpouam SE, Schlecht E (2019). Genetic and nongenetic factors affecting on-farm performance of peri-urban dairy cattle in west Africa. Journal of Dairy Science, 102(3): 2353-2364. DOI: https://doi.org/10.3168/jds.2018-15348

SAS (Statistical Analysis System) (2002) Institute Inc., Cary, NC, USA.

Takele T, Workneh A and Hegde B P (2007). On-farm Characterization of Sheko Breed of Cattle in Southwestern Ethiopia. Ethiopian Journal of Animal Production, 7(1): 89 - 105. Link I Google Scholar

Tatum J D (2011) Animal age, physiological maturity, and associated effects on beef tenderness. White paper Research and Knowledge Management, pp.12. https://www.beefresearch.org/CMDocs/BeefResearch/PE_White_\%2OPapers/Animal_Age.pdf

Zerabruk M, Vangen $O$ and Haile $M$ (2007). The status of cattle genetic resources in North Ethiopia: On-farm characterization of six major cattle breeds. Animal Genetic Resources Information, 40: 15-32. https://doi.org/10.1017/S1014233900002169 